\title{
Deep brain stimulation in children and young adults with secondary dystonia: the Children's Hospital Los Angeles experience
}

\author{
Joffre E. Olaya, M.D., ${ }^{1,2}$ Eisha Christian, M.D., ${ }^{1,2}$ Diana Ferman, P.A.-C.,, 3 \\ Quyen Luc, M.D., ${ }^{3,4}$ Mark D. Krieger, M.D., ${ }^{1,2}$ Terence D. Sanger, M.D., Ph.D., ${ }^{3-5}$ \\ AND MARK A. Liker, M.D. ${ }^{1,2}$ \\ Division of ${ }^{\prime}$ Neurosurgery and ${ }^{3}$ Division of Child Neurology, Children's Hospital Los Angeles; and \\ ${ }^{2}$ Department of Neurological Surgery, ${ }^{7}$ Division of Pediatric Neurology, and ${ }^{5}$ Department of Biomedical \\ Engineering and BioKinesiology, The Keck School of Medicine at USC, University of Southern California, \\ Los Angeles, California
}

\begin{abstract}
Background. Dystonia is a movement disorder in which involuntary sustained or intermittent muscle contractions cause twisting and repetitive movements, abnormal postures, or both. It can be classified as primary or secondary. There is no cure for dystonia and the goal of treatment is to provide a better quality of life for the patient.

Surgical intervention is considered for patients in whom an adequate trial of medical treatment has failed. Deep brain stimulation (DBS), specifically of the globus pallidus interna (GPi), has been shown to be extremely effective in primary generalized dystonia. There is much less evidence for the use of DBS in patients with secondary dystonia. However, given the large number of patients with secondary dystonia, the significant burden on the patients and their families, and the potential for DBS to improve their functional status and comfort level, it is important to continue to investigate the use of DBS in the realm of secondary dystonia.

Object. The objective of this study is to review a series of cases involving patients with secondary dystonia who have been treated with pallidal DBS.

Methods. A retrospective review of 9 patients with secondary dystonia who received treatment with DBS between February 2011 and February 2013 was performed. Preoperative and postoperative videos were scored using the Barry-Albright Dystonia Scale (BADS) and Burke-Fahn-Marsden Dystonia Rating Scale (BFMDRS) by a neurologist specializing in movement disorders. In addition, the patients' families completed a subjective questionnaire to assess the perceived benefit of DBS.

Results. The average age at DBS unit implantation was 15.1 years (range 6-20 years). The average time to followup for the BADS evaluation from battery implantation was 3.8 months (median 3 months). The average time to followup for the subjective benefit evaluation was 10.6 months (median 9.5 months). The mean BADS scores improved by $9 \%$ from 26.5 to $24(p=0.04)$, and the mean BFMDRS scores improved by $9.3 \%(p=0.055)$. Of note, even in patients with minimal functional improvement, there seemed to be decreased contractures and spasms leading to improved comfort. There were no complications such as infections or hematoma in this case series. In the subjective benefit evaluation, 3 patients' families reported "good" benefit, 4 reported "minimal" benefit, and 1 reported no benefit.

Conclusions. These early results of GPi stimulation in a series of 9 patients suggest that DBS is useful in the treatment of secondary generalized dystonia in children and young adults. Objective improvements in BADS and BFMDRS scores are demonstrated in some patients with generalized secondary dystonia but not in others. Larger follow-up studies of DBS for secondary dystonia, focusing on patient age, history, etiology, and patterns of dystonia, are needed to learn which patients will respond best to DBS.

(http://thejns.org/doi/abs/10.3171/2013.8.FOCUS13300)
\end{abstract}

\section{KEY WoRdS • deep brain stimulation • secondary dystonia pediatric neurosurgery}

$\mathrm{D}$ YSTONIA is a movement disorder that causes muscles to involuntarily contract (go into spasm). Specifically, the Taskforce of Childhood Movement Disorders defines it as a disorder in which involuntary sustained or intermittent muscle contractions cause

Abbreviations used in this paper: BADS = Barry-Albright Dystonia Scale; BFMDRS = Burke-Fahn-Marsden Dystonia Rating Scale; CHLA = Children's Hospital Los Angeles; DBS = deep brain stimulation; GPi = globus pallidus interna; IPG = implantable pulse generator; STN = subthalamic nucleus. twisting and repetitive movements, abnormal postures, or both. ${ }^{33}$ Hyperkinetic movements such as these can be seen in a plethora of neurological disorders ${ }^{33}$ and can make diagnosis challenging.

Dystonia can be classified as either primary or secondary. Primary generalized or idiopathic torsion dystonia is defined by involvement of more than one body part, familial predisposition, and a lack of additional neurological symptoms or other etiology. Primary dystonia has been linked with multiple gene loci, with the most commonly involved and best-studied gene being DYTl. Secondary 
dystonia can be caused by many environmental factors that injure the brain, including stroke, encephalopathy, trauma, hypoxic injury, or infection. ${ }^{3,38}$ Even though the most common type of secondary dystonia is categorized as cerebral palsy, ${ }^{33}$ patients with secondary dystonia represent a varied population with many different underlying pathophysiologies and potential responses to treatment. ${ }^{3}$

At this time, there is no cure for dystonia. The goal of treatment is to provide a better quality of life for the patient. This can be done directly, by relieving pain and immobility related to dystonic contractions and thereby improving functional ability, ${ }^{32}$ and indirectly, by providing caregivers with a more manageable child. Dystonia can be treated medically with anticholinergics, antidopaminergic agents, baclofen (oral or intrathecal), or benzodiazepines. ${ }^{3,32}$ Patients should be provided with a trial of levodopa in case they are among the few who have doparesponsive dystonia., ${ }^{3,32}$ Patients with focal or segmental dystonia can be treated with injections of botulinum toxin, but this treatment is not very effective in patients with generalized dystonia.,32 Therefore, we usually use combination therapy of oral medications and injectable botulinum toxin to achieve treatment goals for our patients.

Patients in whom medical treatment fails are considered for surgery. Neurosurgical treatments of dystonia have included thalamotomy, ${ }^{8,18,37}$ dorsal column stimulation, ${ }^{16}$ cerebellar stimulation,,${ }^{10}$ pallidotomy, ${ }^{20}$ and intrathecal baclofen therapy via an implanted pump. ${ }^{2}$ Pallidotomy has been shown to improve primary dystonia, but unilateral pallidotomy may not be sufficient for generalized symptoms and bilateral pallidotomy is associated with significant risk. ${ }^{3,29}$ Also, the irreversibility of parenchymal lesioning favors the use of nonablative deep brain stimulation (DBS) technology.

DBS has been shown to be most effective in patients with primary generalized dystonia, and patients with a DYT1 mutation are reported to have the best response. ${ }^{3,30}$ Although patients with primary dystonia respond best, patients with secondary dystonia have also experienced improvement with DBS. 22

It has been challenging to assess the benefits of DBS, particularly in children with secondary dystonia. The most commonly used scale has been the Burke-FahnMarsden Dystonia Rating Scale (BFMDRS); ${ }^{7}$ however, some authors have also used a modified BFMDRS known as the Barry-Albright Dystonia Scale (BADS)., ${ }^{1,26}$ This scale was specifically developed to assess patients with secondary dystonia. ${ }^{4}$ The BFMDRS assesses movement primarily related to function, but many patients with secondary dystonia have significant cognitive impairments, making it difficult to assess their voluntary control of movements and ultimate functional capacity. ${ }^{4}$

\section{Methods}

Nine patients with secondary dystonia (6 male and 3 female) were included in this study. Their ages ranged from 6 to 20 years (mean $15.1 \pm 5.51$ years [SD]). Secondary dystonia was diagnosed by an experienced pediatric neurologist, and the patients were also evaluated by two neurosurgeons. Ratings were performed by a pediatric neurologist with a specialty in movement disorders, a neurosurgeon, and a physician assistant.

Deep brain stimulation of the globus pallidus interna (GPi) was conducted by one neurosurgeon. Multiple authors have described the surgical procedure in detail. ${ }^{12} \mathrm{We}$ will highlight some of the differences in our approach. With the patient under heavy sedation (intravenously administered propofol) in addition to local anesthesia, a Cosman-Roberts-Wells frame is affixed to the patient's head. In the pediatric population, the thickness of the cranial vault is a consideration when placing pins, and children under the age of 5 years have been excluded from this procedure. A thin-cut CT is obtained with the fiducial box in place, and the images are combined with previously obtained T1- and T2-weighted MR images to assist in the targeting of the posteroventral GPi. Due to perceived renal-system risk, intravenous contrast is not used during the acquisition of the CT or MR images. Via the head frame, the patient's head is affixed to the operating table with the patient in a semisitting position. Once drilling commences, anesthesia (propofol and dexmedetomidine) is discontinued. We have identified a significant delay in the time required for patients with secondary dystonia to awaken as compared with adults undergoing DBS surgery, and we attempt to make accommodations for this. A bilateral GPi implantation procedure is planned for each new patient. The dominant hemisphere is generally the first side targeted. A 3-microelectrode array configuration consisting of a central, medial, and posterior trajectory is implanted. The central trajectory represents the calculated DBS position using both direct and indirect targeting of the GPi, and the medial trajectory represents the optic tract target. If an adequate traversal distance of $4 \mathrm{~mm}$ is identified through the GPi with minimal macrostimulation side effects, we use a single microelectrode for the contralateral procedure. Medtronic Model 3387 permanent quadripolar electrodes were used in all cases. A Medtronic Activa PC implantable pulse generator (IPG) was preferred but for small children the Activa SC was recommended (Table 1). All IPGs were implanted in a subclavicular location.

In addition to this surgical protocol, given the high rate of infections in pediatric patients undergoing DBS surgery, we also instituted a stringent antibiotic protocol. Vancomycin and ceftazidime were administered preoperatively, and intravenous treatment with these 2 medications was continued for 72 hours; patients remained in the hospital for 3

TABLE 1: Surgical implants and targets

\begin{tabular}{ccll}
\hline Patient & \multicolumn{1}{c}{ Lead } & \multicolumn{1}{c}{ Target } & \multicolumn{1}{c}{ Battery } \\
\hline Patient A & Medtronic 3387 & GPi & Activa PC \\
Patient B & Medtronic 3387 & GPi & Kinetra \\
Patient C & Medtronic 3387 & STN, GPi & Activa PC \\
Patient D & Medtronic 3387 & GPi & Activa SC \\
Patient E & Medtronic 3387 & GPi & Activa PC \\
Patient F & Medtronic 3387 & GPi & Activa SC \\
Patient G & Medtronic 3387 & GPi & Activa SC \\
Patient H & Medtronic 3387 & GPi & Activa Rechargeable \\
Patient I & Medtronic 3387 & GPi & Activa PC \\
\hline
\end{tabular}


days while completing this course of therapy. In addition, patients were treated with orally administered dicloxacillin for 2 weeks after being discharged home. The pulse generator was implanted after completion of this regimen.

\section{Results}

\section{Participants}

During the past 5 years, 12 patients with dystonia underwent implantation of DBS units at the Children's Hospital Los Angeles (CHLA). Of these patients, 9 had secondary dystonia. Eight patients had postoperative videos available for evaluation.

\section{Descriptive Data}

The patients' demographic information is outlined in Table 2 . Their mean age at surgery was 15.1 years (range 6-20 years). Six male and 3 female patients were included in the study. Six patients had dystonia secondary to cerebral palsy, 2 patients secondary to kernicterus, and 1 secondary to anoxic brain injury after a drug overdose. The average time from IPG implantation to follow-up for the BADS evaluation was 3.8 months (median 3 months). The average time to follow-up for the subjective benefit scale was 10.6 months (median 9.5 months).

\section{Clinical Efficacy of DBS}

Barry-Albright Dystonia Scale. A summary of the BFMDRS and BADS scores is presented in Table 3. The majority of patients in this review underwent DBS surgery in the last 2 years, and therefore our follow-up time is limited. The median time to follow-up for BADS scoring was 3 months and based on video examinations. The average preoperative BADS score was 26.5 which improved to 24 postoperatively $(\mathrm{p}=0.04)$ with an average $9 \%$ improvement in scores. However, given the limited number of patients, there was a high variability in scoring.

Burke-Fahn-Marsden Dystonia Rating Scale. The BFMDRS score has been used more frequently than the BADS scores in previous dystonia outcome studies. The average BFMDRS score showed an improvement of 8 (p $=0.055$ ) from an average preoperative score of 86.4 to an average postoperative score of 78.5 (9.3\%).

\section{TABLE 2: Summary of patient clinical and demographic} characteristics

\begin{tabular}{ccl}
\hline Patient & Age (yrs), Sex & \multicolumn{1}{c}{ Etiology } \\
\hline Patient A & $20, \mathrm{M}$ & anoxic brain injury \\
Patient B & $16, \mathrm{M}$ & cerebral palsy \\
Patient C & $20, \mathrm{M}$ & cerebral palsy \\
Patient D & $10, \mathrm{M}$ & kernicterus \\
Patient E & $20, \mathrm{~F}$ & cerebral palsy \\
Patient F & $20, \mathrm{M}$ & cerebral palsy \\
Patient G & $19, \mathrm{~F}$ & cerebral palsy \\
Patient H & $6, \mathrm{M}$ & cerebral palsy \\
Patient I & $16, \mathrm{~F}$ & kernicterus \\
\hline
\end{tabular}

Subjective Benefit Rating Scale. The BADS scores reflected the functional improvement after DBS unit implantation. However, this scoring failed to capture the increased comfort levels due to decreased contractures and decreases in sustained spasm. Even though functionality may not have tremendously increased, all patients on video evaluation had improved contractures and improved comfort levels. To capture this, we used a subjective benefit rating scale, asking caregivers to assess the results of DBS as follows: -1 (worse), 0 (no benefit), 1 (minimal benefit), 2 (good benefit), 3 (excellent benefit). The results are shown in Table 4 . The median subjective benefit rating was 1 , showing minimal benefit.

An overall summary of our 9 cases and the results achieved with DBS is shown in Table 5. Again, these results are limited due to the subjective nature of the rating and the limited number of patients.

\section{Illustrative Cases}

Accompanying this article are videos clips that show results in 3 of our 9 patients (Patients $\mathrm{A}, \mathrm{B}$, and $\mathrm{C}$ ).

Patient A is a 20-year-old male who has dystonia secondary to anoxic brain injury from a drug overdose. He showed marked functional improvements, and his BADS score changed from 27 before DBS surgery to 21 with DBS. He was bedridden prior to surgery but is now able to ambulate with assistance (Video 1).

VIDEO 1. Video clip showing preoperative and postoperative evaluation of Patient A. Copyright Mark Liker. Published with permission. Click here to view with Media Player. Click here to view with Quicktime.

Patient B is a 16-year-old male who has dystonia secondary to cerebral palsy. The changes in his BADS and BFMDRS scores were minimal; however, his postoperative video demonstrates that he has improvement with respect to contractions and some improved control of his extremities. We highlight this patient as an example of someone who may not have shown functional improvement but did have improved comfort from decreased contractures (Video 2).

VIDEO 2. Video clip showing preoperative and postoperative evaluation of Patient B. Copyright Mark Liker. Published with permission. Click here to view with Media Player. Click here to view with Quicktime.

Patient $\mathrm{C}$ is a 20 -year-old male with dystonia secondary to cerebral palsy. Of note, he had both GPi and subthalamic nucleus (STN) stimulators. His BADS scores improved from 27 to 19, and he went from being bedridden with extreme contractures to being able to ambulate with assistance (Video 3).

VIDEo 3. Video clip showing preoperative and postoperative evaluation of Patient C. Copyright Mark Liker. Published with permission. Click here to view with Media Player. Click here to view with Quicktime.

\section{Discussion}

The safety and efficacy of DBS for primary dystonia in children and adults, particularly in those with a DYT1 mutation, has been established by several groups.,3,6,11, 
TABLE 3: Scores on BADS and BFMDRS*

\begin{tabular}{|c|c|c|c|c|c|c|c|}
\hline Patient & Preop BADS & Postop BADS & $\%$ Change & $\begin{array}{c}\text { Preop } \\
\text { BFMDRS }\end{array}$ & $\begin{array}{c}\text { Postop } \\
\text { BFMDRS }\end{array}$ & $\%$ Change & $\begin{array}{c}\text { Time to } \\
\text { Follow-Up (mos) }\end{array}$ \\
\hline Patient A & 27 & 21 & 22.22 & 82 & 57.5 & 29.88 & 1 \\
\hline Patient B & 28 & 25 & 10.71 & 90.5 & 90.5 & 0.00 & 1 \\
\hline Patient C & 27 & 19 & 29.63 & 90 & 53.5 & 40.56 & 5 \\
\hline Patient D & 26 & 26 & 0.00 & 94.5 & 94.5 & 0.00 & 8 \\
\hline Patient E & 25 & 24 & 4.00 & 108 & 108 & 0.00 & 9 \\
\hline Patient F & 20 & 20 & 0.00 & 58 & 53.5 & 7.76 & 3 \\
\hline Patient G & 29 & 29 & 0.00 & 106 & 100 & 5.66 & 3 \\
\hline Patient H & 27 & 28 & -3.70 & 76 & 76 & 0.00 & 0.5 \\
\hline Patient I & 26 & NA & NA & 73 & NA & NA & NA \\
\hline
\end{tabular}

* NA = not available.

13,19,21,28,30-32,35,38,39 However, there have only been a few reports regarding DBS for secondary dystonia, ${ }^{22,40}$ with a very limited number of pediatric cases reported (Table 6). ${ }^{1,3,13,23,24,26,42}$ Cerebral palsy is the most common cause of secondary dystonia. ${ }^{33}$ The incidence of cerebral palsy is approximately 2 per 1000 births. ${ }^{41}$ There is no cure for dystonia, and DBS could therefore potentially improve the lives of a considerable number of patients who suffer from this condition.

Vayssiere et al. reported on a series of 35 children with dystonia treated with DBS. The 10 children who had secondary dystonia had a $31 \%$ improvement in BFMDRS scores. ${ }^{38}$ Similarly, Alterman and Tagliati reported a 33\% improvement in BFMDRS motor scores in the 5 pediatric patients with secondary dystonia in their series. ${ }^{3}$ Ghosh et al. reported a $31.3 \%$ improvement in BFMDRS motor scores and a $37.5 \%$ improvement BFMDRS disability scores in their 2 pediatric patients with secondary dystonia. ${ }^{13}$ Air et al. had 11 pediatric patients with secondary dystonia in their series; however, they only reported outcomes in 4, and their results were more modest than the prior studies. ${ }^{1}$ Three patients had a $10 \%$ improvement in the BFMDRS motor score and a $20 \%$ improvement in the disability score. In one patient they reported the outcome in terms of BADS score which improved by $22 \%$.

TABLE 4: Scores on the subjective benefit rating scale from caregivers*

\begin{tabular}{ccc}
\hline Patient & Time to Follow-Up (mos) & Score \\
\hline Patient A & 4 & 1 \\
Patient B & 13 & 1 \\
Patient C & 12 & 2 \\
Patient D & 17 & 1 \\
Patient E & 29 & 0 \\
Patient F & NA & NA \\
Patient G & 7 & 1 \\
Patient H & 2 & 2 \\
Patient I & 1 & 2
\end{tabular}

* Scored as follows: $-1=$ worse; $0=$ no benefit; $1=$ minimal benefit; 2

= good benefit; 3 = excellent benefit.
Marks et al. evaluated all of the patients in their series using BFMDRS and BADS scores. They also relied on patient and caretaker reports and serial video assessments to monitor treatment response, since scores alone do not detect subtle changes that may represent significant functional improvements in individual patients. ${ }^{25}$ In their initial series of 8 patients younger than 16 years with cerebral palsy-related dystonia who were treated with DBS, they saw a $37.84 \%$ improvement in BFMDRS motor scores, a $14.44 \%$ improvement in BFMDRS disability scores, and a $19.48 \%$ improvement in BADS scores at 6-month followup. However, the 6 patients who were older than 16 years only had an improvement of $8.96 \%, 1.63 \%$, and $1.39 \%$ in BFMDRS motor, BFMDRS disability, and BADS scores, respectively. ${ }^{26}$ In a follow-up study in which they compared patients with cerebral palsy and patients with DYTI dystonia after DBS unit placement, they found that gains reported at 6 months in the cerebral palsy group were sustained at 18 -month follow-up. ${ }^{24}$ The DYT1 group, on the other hand, continued to improve even after 18 months. ${ }^{24}$

Zorzi et al. reported on 3 patients with secondary

TABLE 5: Summary of 9 cases

\begin{tabular}{ll}
\hline \multicolumn{1}{c}{ Variable } & \multicolumn{1}{c}{ Value } \\
\hline median age & $19 \mathrm{yrs}$ \\
median follow-up (BADS evaluation) & $3 \mathrm{mos}$ \\
median preop BADS score & 27 \\
average preop BADS score & 26.5 \\
median postop BADS score & 24.5 \\
average postop BADS score & 24 \\
average improvement in BADS & $2.25(\mathrm{p}=0.04)$ \\
median follow-up (subjective benefit score) & $9.5 \mathrm{mos}$ \\
average subjective benefit score & 1.25 \\
median subjective benefit score & 1 \\
average preop BFMDRS score & 86.4 \\
median preop BFMDRS score & 90 \\
average postop BFMDRS score & 78.5 \\
median postop BFMDRS score & 76 \\
average improvement in BFMDRS & $8(\mathrm{p}=0.055)$ \\
\hline
\end{tabular}


DBS for secondary dystonia: the CHLA experience

TABLE 6: Summary of previously published reports of DBS for secondary dystonia in children and young adults*

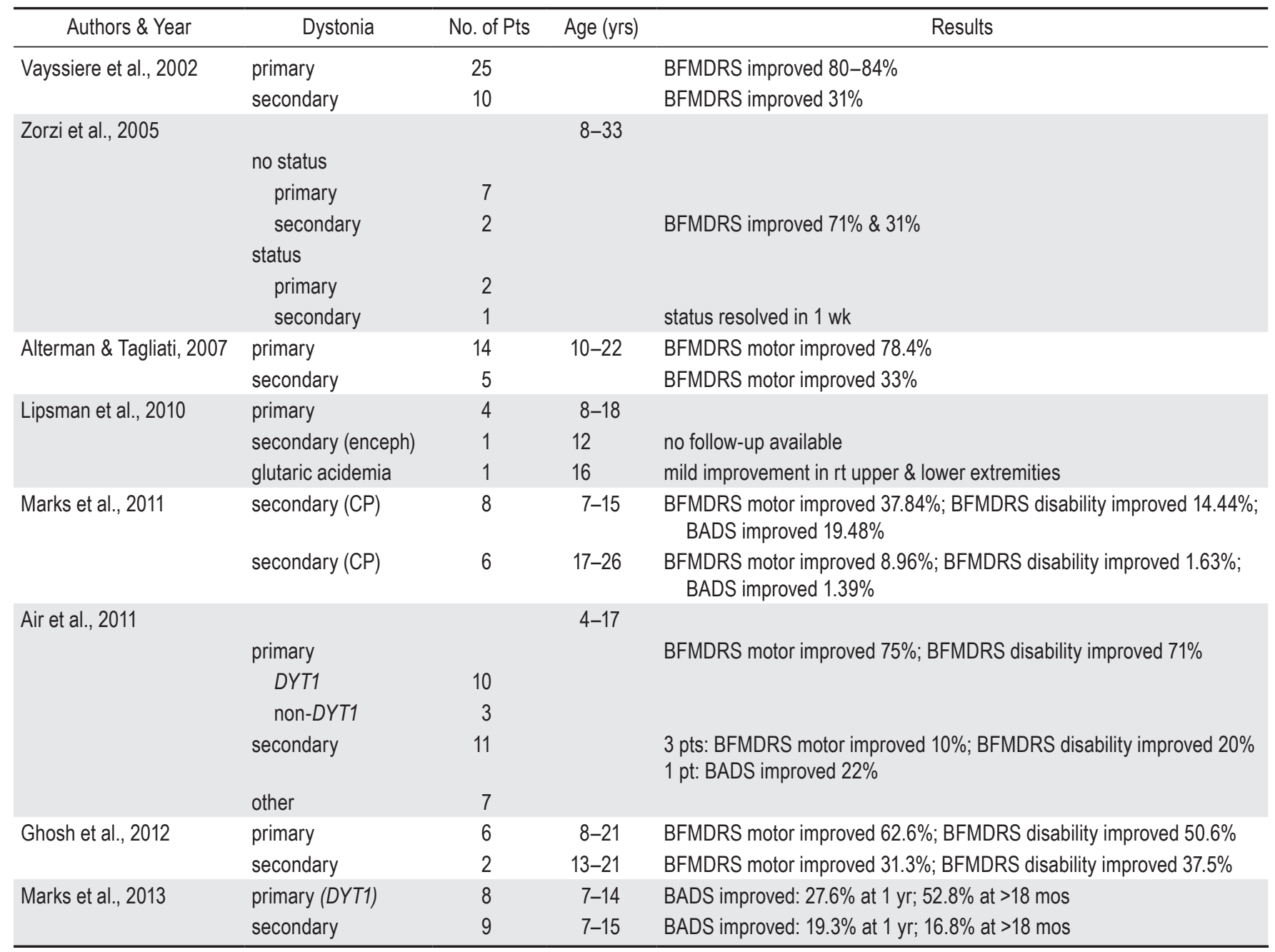

${ }^{*} \mathrm{CP}=$ cerebral palsy; enceph = encephalopathy; pts = patients.

dystonia treated with DBS. ${ }^{42}$ The 2 patients who were not in status dystonicus had overall improvement in BFMDRS scores of $31 \%$ and $71 \%$. The 1 patient with secondary dystonia who was in status dystonicus prior to surgery had resolution of status dystonicus 1 week after surgery. ${ }^{42}$ Lipsman et al. reported on a patient with secondary dystonia who was treated with DBS in their series. However, they did not have any follow-up data for this patient. ${ }^{23}$

A recent meta-analysis of 20 articles including 68 pediatric and adult patients with cerebral palsy showed a $23.6 \%$ improvement in the BFMDRS motor score and a $9.2 \%$ improvement in the BFMDRS disability score. ${ }^{22}$ To date, the results based on the rating scales that are currently being used have been modest; however, these scales may not fully reflect the benefits that these patients receive from DBS.

Some authors have proposed using other outcome measures to better assess children with secondary dystonia after DBS unit placement. ${ }^{15}$ Specifically, Gimeno et al. suggest using tools such as the Canadian Occupational Performance Measure (COPM) and goal attainment scal- ing (GAS) to identify concerns and functional changes which are important to the child and family and measure the extent to which families feel both performance and satisfaction have changed in these areas..$^{15}$ These tools assess important concerns such as pain, comfort, ability to attend school, sitting tolerance, daily care, and burden to caregiver. ${ }^{15}$ In another study, this group has also looked at improvements in upper limb function in dystonic children after DBS. Their data can be used to guide children and their families in terms of goals and time frame for clinical improvements after DBS. ${ }^{14}$

DBS surgery in dystonic children has its own unique challenges. Pediatric patients may not be as cooperative as their adult counterparts, and some children may have severe spontaneous dystonic spasms, which may not allow them to hold still for the length of the surgery. Some groups have chosen to perform these procedures in children under general anesthesia forgoing microelectrode recording confirmation of lead placement. ${ }^{39}$ Vayssiere et al. showed that MRI-based DBS lead placement alone can be reliable for GPi target localization in children with primary dystonia. ${ }^{39}$ 
In a subsequent study this group also showed that MRIbased targeting of the GPi had good results in a mixed population of pediatric and adult patients with either primary or secondary dystonia, showing a $31 \%$ improvement in BFMDRS scores in patients with secondary dystonia. ${ }^{38}$

Other groups have proposed that microelectrode recording provides important information for adequate lead placement in the GPi. ${ }^{3,35}$ Starr et al. have shown good lead placement in a mixed group of patients with different types of dystonia using microelectrode recording with few serious complications. ${ }^{35}$ They have shown that even in patients who needed to be under general anesthesia they could achieve adequate mapping, but cautioned that propofol and inhalational agents should be avoided for optimal preservation of neuronal firing. ${ }^{35}$ Dexmedetomidine has been successfully used during DBS surgery in dystonic children, providing adequate sedation and analgesia without causing respiratory depression and allowing for patient cooperation during neurophysiological mapping. ${ }^{27,34}$ Nevertheless, intraoperative testing for dystonic patients may not be as useful as for patients with Parkinson's disease or essential tremor because it may take weeks before any clinical benefits are appreciated. .,39 $^{3}$

DBS surgery has associated risks that we should counsel our patients and their families about. In the series for which authors reported complications after DBS surgery, postoperative infection was seen in up to $21 \%$ of pediatric patients with dystonia., ${ }^{1,3,13}$ This was comparable to infection rates seen in this patient population after placement of other implants, such as baclofen pumps. ${ }^{2}$ Air et al. reported that all of their infections were in patients younger than 10 years of age. ${ }^{1}$ Hardware failures were seen in up to $25 \%$ of patients with dystonia treated with DBS. ${ }^{3,13}$ Other complications, although not reported in the above studies, include serious hemorrhage ${ }^{5}$ and venous air embolism. ${ }^{17}$

Given this history of high postoperative infection rates in dystonic children who undergo DBS surgery, we enforced a stringent antibiotic protocol at CHLA that included 72 hours of intravenous vancomycin and ceftazidime followed by a 2-week course of oral dicloxacillin prior to IPG insertion. We had no infections or additional complications such as hematoma in our patients.

Our study has multiple limitations. 1) We only have 9 patients at this time, which limits the power of this study. 2) Our patient population is heterogeneous with respect to etiology and age, which further confounds our small sample size. 3) Given the recent nature of the implantation procedures, we do not have long follow-up. 4) Our BADS and BFMDRS scoring was not blinded, which could have influenced our scoring method. Susatia et al. found that if clinicians rating the videos of dystonic patients treated with DBS were blinded, the overall improvement scores were lower than if the videos were rated by the unblinded treating neurologist. ${ }^{36}$

\section{Conclusions}

There is conclusive literature that supports DBS as a treatment option for patients with medically refractory primary dystonia. However, DBS for secondary dysto- nia is still controversial, as there are only limited data from this varied patient population..$^{25}$ Our study, although limited by a small patient population, shows that there is some statistically significant functional improvement with DBS. However, the BADS and BFMDRS fail to capture the effect on patient comfort that we see after DBS. A significant discrepancy therefore exists between the scoring systems used to rate secondary generalized dystonia and the subjective benefit identified by families and caregivers. This highlights the need to identify a more inclusive scale or rating system that takes patient comfort from decreased spasms and contractures into account. Multicenter studies involving patients with secondary dystonia are needed to learn which types of secondary dystonia will respond best to DBS. In this paper we report early results of a retrospective review of GPi stimulation suggesting that DBS is useful in the treatment of secondary generalized dystonia in children and young adults.

\section{Disclosure}

The authors report no conflict of interest concerning the materials or methods used in this study or the findings specified in this paper.

Author contributions to the study and manuscript preparation include the following. Conception and design: Liker, Olaya, Ferman, Sanger. Acquisition of data: Liker, Christian, Ferman. Analysis and interpretation of data: Liker, Christian, Ferman, Luc. Drafting the article: Liker, Olaya, Christian, Ferman. Critically revising the article: Liker, Olaya, Christian, Ferman. Reviewed submitted version of manuscript: Liker, Olaya, Christian, Sanger. Statistical analysis: Christian. Administrative/technical/material support: Olaya, Christian, Ferman. Study supervision: Liker, Olaya, Krieger, Sanger.

\section{References}

1. Air EL, Ostrem JL, Sanger TD, Starr PA: Deep brain stimulation in children: experience and technical pearls. Clinical article. J Neurosurg Pediatr 8:566-574, 2011

2. Albright AL: Neurosurgical treatment of spasticity and other pediatric movement disorders. J Child Neurol 18 (Suppl 1): S67-S78, 2003

3. Alterman RL, Tagliati M: Deep brain stimulation for torsion dystonia in children. Childs Nerv Syst 23:1033-1040, 2007

4. Barry MJ, VanSwearingen JM, Albright AL: Reliability and responsiveness of the Barry-Albright Dystonia Scale. Dev Med Child Neurol 41:404-411, 1999

5. Ben-Haim S, Asaad WF, Gale JT, Eskandar EN: Risk factors for hemorrhage during microelectrode-guided deep brain stimulation and the introduction of an improved microelectrode design. Neurosurgery 64:754-763, 2009

6. Borggraefe I, Mehrkens JH, Telegravciska M, Berweck S, Bötzel K, Heinen F: Bilateral pallidal stimulation in children and adolescents with primary generalized dystonia-report of six patients and literature-based analysis of predictive outcomes variables. Brain Dev 32:223-228, 2010

7. Burke RE, Fahn S, Marsden CD, Bressman SB, Moskowitz C, Friedman J: Validity and reliability of a rating scale for the primary torsion dystonias. Neurology 35:73-77, 1985

8. Cooper IS: 20-year followup study of the neurosurgical treatment of dystonia musculorum deformans. Adv Neurol 14:423452, 1976

9. Coubes P, Cif L, El Fertit H, Hemm S, Vayssiere N, Serrat S, et al: Electrical stimulation of the globus pallidus internus in patients with primary generalized dystonia: long-term results. J Neurosurg 101:189-194, 2004 
10. Davis R, Bloedel JR: Cerebellar Stimulation for Spasticity and Seizures. Boca Raton, FL: CRC Press, 1984

11. Egidi M, Franzini A, Marras C, Cavallo M, Mondani M, Lavano A, et al: A survey of Italian cases of dystonia treated by deep brain stimulation. J Neurosurg Sci 51:153-158, 2007

12. Follett KA, Weaver FM, Stern M, Hur K, Harris CL, Luo P, et al: Pallidal versus subthalamic deep-brain stimulation for Parkinson's disease. N Engl J Med 362:2077-2091, 2010

13. Ghosh PS, Machado AG, Deogaonkar M, Ghosh D: Deep brain stimulation in children with dystonia: experience from a tertiary care center. Pediatr Neurosurg 48:146-151, 2012

14. Gimeno H, Lumsden D, Gordon A, Tustin K, Ashkan K, Selway R, et al: Improvement in upper limb function in children with dystonia following deep brain stimulation. Eur J Paediatr Neurol 17:353-360, 2013

15. Gimeno H, Tustin K, Selway R, Lin JP: Beyond the BurkeFahn-Marsden Dystonia Rating Scale: deep brain stimulation in childhood secondary dystonia. Eur J Paediatr Neurol 16: 501-508, 2012

16. Goetz CG, Penn RD, Tanner CM: Efficacy of cervical cord stimulation in dystonia. Adv Neurol 50:645-649, 1988

17. Gooden CK, Osborn IP: Venous air embolism during deep brain stimulation surgery in an awake child. Can J Anaesth 57:88-89, 2010

18. Gros C, Frerebeau P, Perez-Dominguez E, Bazin M, Privat JM: Long term results of stereotaxic surgery for infantile dystonia and dyskinesia. Neurochirurgia (Stuttg) 19:171-178, 1976

19. Haridas A, Tagliati M, Osborn I, Isaias I, Gologorsky Y, Bressman SB, et al: Pallidal deep brain stimulation for primary dystonia in children. Neurosurgery 68:738-743, 2011

20. Iacono RP, Kuniyoshi SM, Lonser RR, Maeda G, Inae AM, Ashwal S: Simultaneous bilateral pallidoansotomy for idiopathic dystonia musculorum deformans. Pediatr Neurol 14: 145-148, 1996

21. Jin ST, Lee MK, Ghang JY, Jeon SM: Deep brain stimulation of the globus pallidus in a 7-year-old girl with DYT1 generalized dystonia. J Korean Neurosurg Soc 52:261-263, 2012

22. Koy A, Hellmich M, Pauls KA, Marks W, Lin JP, Fricke O, et al: Effects of deep brain stimulation in dyskinetic cerebral palsy: a meta-analysis. Mov Disord 28:647-654, 2013

23. Lipsman N, Ellis M, Lozano AM: Current and future indications for deep brain stimulation in pediatric populations. Neurosurg Focus 29(2):E2, 2010

24. Marks W, Bailey L, Reed M, Pomykal A, Mercer M, Macomber D, et al: Pallidal stimulation in children: comparison between cerebral palsy and DYT1 dystonia. J Child Neurol 28:840-848, 2013

25. Marks WA, Honeycutt J, Acosta F, Reed M: Deep brain stimulation for pediatric movement disorders. Semin Pediatr Neurol 16:90-98, 2009

26. Marks WA, Honeycutt J, Acosta F Jr, Reed M, Bailey L, Pomykal A, et al: Dystonia due to cerebral palsy responds to deep brain stimulation of the globus pallidus internus. Mov Disord 26:1748-1751, 2011

27. Maurtua MA, Cata JP, Martirena M, Deogaonkar M, Rezai A, Sung W, et al: Dexmedetomidine for deep brain stimulator placement in a child with primary generalized dystonia: case report and literature review. J Clin Anesth 21:213-216, 2009

28. Mehrkens JH, Borggraefe I, Feddersen B, Heinen F, Bötzel $\mathrm{K}$ : Early globus pallidus internus stimulation in pediatric patients with generalized primary dystonia: long-term efficacy and safety. J Child Neurol 25:1355-1361, 2010

29. Ondo WG, Desaloms JM, Jankovic J, Grossman RG: Pallidotomy for generalized dystonia. Mov Disord 13:693-698, 1998

30. Panov F, Gologorsky Y, Connors G, Tagliati M, Miravite J, Alterman RL: Deep brain stimulation in DYT1 dystonia: a 10-year experience. Neurosurgery 73:86-93, 2013

31. Parr JR, Green AL, Joint C, Andrew M, Gregory RP, Scott $\mathrm{RB}$, et al: Deep brain stimulation in childhood: an effective treatment for early onset idiopathic generalised dystonia. Arch Dis Child 92:708-711, 2007

32. Roubertie A, Echenne B, Cif L, Vayssiere N, Hemm S, Coubes P: Treatment of early-onset dystonia: update and a new perspective. Childs Nerv Syst 16:334-340, 2000

33. Sanger TD, Chen D, Fehlings DL, Hallett M, Lang AE, Mink JW, et al: Definition and classification of hyperkinetic movements in childhood. Mov Disord 25:1538-1549, 2010

34. Sebeo J, Deiner SG, Alterman RL, Osborn IP: Anesthesia for pediatric deep brain stimulation. Anesthesiol Res Pract 2010:401419, 2010

35. Starr PA, Turner RS, Rau G, Lindsey N, Heath S, Volz M, et al: Microelectrode-guided implantation of deep brain stimulators into the globus pallidus internus for dystonia: techniques, electrode locations, and outcomes. J Neurosurg 104: 488-501, 2006

36. Susatia F, Malaty IA, Foote KD, Wu SS, Zeilman PR, Mishra M, et al: An evaluation of rating scales utilized for deep brain stimulation for dystonia. J Neurol 257:44-58, 2010

37. Tasker RR, Doorly T, Yamashiro K: Thalamotomy in generalized dystonia. Adv Neurol 50:615-631, 1988

38. Vayssiere N, Hemm S, Cif L, Picot MC, Diakonova N, El Fertit $\mathrm{H}$, et al: Comparison of atlas- and magnetic resonance imaging-based stereotactic targeting of the globus pallidus internus in the performance of deep brain stimulation for treatment of dystonia. J Neurosurg 96:673-679, 2002

39. Vayssiere N, Hemm S, Zanca M, Picot MC, Bonafe A, Cif L, et al: Magnetic resonance imaging stereotactic target localization for deep brain stimulation in dystonic children. J Neurosurg 93:784-790, 2000

40. Vidailhet M, Yelnik J, Lagrange C, Fraix V, Grabli D, Thobois S, et al: Bilateral pallidal deep brain stimulation for the treatment of patients with dystonia-choreoathetosis cerebral palsy: a prospective pilot study. Lancet Neurol 8:709-717, 2009

41. Winter S, Autry A, Boyle C, Yeargin-Allsopp M: Trends in the prevalence of cerebral palsy in a population-based study. Pediatrics 110:1220-1225, 2002

42. Zorzi G, Marras C, Nardocci N, Franzini A, Chiapparini L, Maccagnano E, et al: Stimulation of the globus pallidus internus for childhood-onset dystonia. Mov Disord 20:1194-1200, 2005

\section{Manuscript submitted July 18, 2013.}

Accepted August 19, 2013.

Please include this information when citing this paper: DOI: 10.3171/2013.8.FOCUS13300.

Supplemental online information:

Video 1: http://mfile.akamai.com/21490/wmv/digitalwbc.download. akamai.com/21492/wm.digitalsource-na-regional/focus13-300_ video_1.asx (Media Player).

http://mfile.akamai.com/21488/mov/digitalwbc.download.akamai. com/21492/qt.digitalsource-global/focus13-300_video_1.mov (Quicktime).

Video 2: http://mfile.akamai.com/21490/wmv/digitalwbc.download. akamai.com/21492/wm.digitalsource-na-regional/focus13-300_ video_2.asx (Media Player).

http://mfile.akamai.com/21488/mov/digitalwbc.download.akamai. com/21492/qt.digitalsource-global/focus13-300_video_2.mov (Quicktime).

Video 3: http://mfile.akamai.com/21490/wmv/digitalwbc.download. akamai.com/21492/wm.digitalsource-na-regional/focus13-300_ video_3.asx (Media Player).

http://mfile.akamai.com/21488/mov/digitalwbc.download.akamai. com/21492/qt.digitalsource-global/focus13-300_video_3.mov (Quicktime).

Address correspondence to: Mark A. Liker, M.D., 1200 N. State St., Ste. 3300, Los Angeles, CA 90033. email: liker@usc.edu. 